\author{
Marquette University \\ e-Publications@Marquette
}

Electrical and Computer Engineering Faculty

Research and Publications

Electrical and Computer Engineering,

Department of

\title{
Enhancing the thermal performance of temporary fabric structures for the advanced energy efficient shelter system
}

Justin E. Eshleman

Air Force Institute of Technology

Robert A. Lake

Air Force Institute of Technology

Ronald A. Coutu Jr.

Marquette University, ronald.coutu@marquette.edu

Follow this and additional works at: https://epublications.marquette.edu/electric_fac

Part of the Computer Engineering Commons, and the Electrical and Computer Engineering Commons

\section{Recommended Citation}

Eshleman, Justin E.; Lake, Robert A.; and Coutu, Ronald A. Jr., "Enhancing the thermal performance of temporary fabric structures for the advanced energy efficient shelter system" (2016). Electrical and Computer Engineering Faculty Research and Publications. 423.

https://epublications.marquette.edu/electric_fac/423 


\title{
Enhancing the Thermal Performance of Temporary Fabric Structures for the Advanced Energy Efficient Shelter System
}

\author{
Justin E. Eshleman, Robert A. Lake, Ronald A. Coutu, Jr. \\ Department of Electrical and Computer Engineering \\ Air Force Institute of Technology \\ Wright Patterson AFB, OH, USA \\ justin.eshleman@afit.edu
}

\begin{abstract}
The focus of this research is to characterize the thermal load on temporary fabric shelters deployed in the Middle East in order to establish realistic contract specification for the thermal performance of future shelters. Three different testing methods were utilized to evaluate shelter thermal performance. Small-scale tests allowed for economical comparisons of different shelter materials and configurations.
\end{abstract}

Keywords-energy-efficiency; temporary fabric structures; radiant barriers;

\section{INTRODUCTION}

Dependency on fossil fuels is a major liability in contingency environments. Integrating alternative energies and increasing the energy-efficiency of operational equipment increases tactical abilities and mitigates risk to mission by reducing fuel supply convoys. Consequently, the Department of Defense (DoD) is focused on reducing the cooling load required for the inherently inefficient temporary fabric shelters, which makes up an estimated $60 \%$ of the overall base operating support electrical load. For this reason, the Air Force and Army joined in a group project to develop and demonstrate deployable Advanced Energy Efficient Shelter Systems with the short term goal to be $50 \%$ more energyefficient than the current generation of shelters and ultimate goal of net zero energy. This will be achieved using solar cells and radiant barriers integrated into the tent fabric, new insulating liners, hardscaped doors, and other upgrades. Little information is available on testing the thermal performance of radiant barriers integrated into fabric structures. This research will review possible testing methods and key variables related to thermal performance.

Optimizing the thermal performance of fabric shelter systems result in massive point-of-use power savings in the deployed environment. The amount of fuel required to power Environmental Control Units (ECUs) can be reduced, along with the number of ECUs. This equates to fuel cost savings and decreases the amount of fuel convoys, mitigating the risk to troops assigned to deliver the fuel to austere locations [1]. Additionally, reducing dependency on fuel allows for increased range and force maneuverability [2].
Insulation techniques such as batt and loose fill insulation used in traditional construction do not meet the compact, lightweight requirements for temporary fabric structure systems in the deployed environment. Also, reflective aluminum used in common insulation interferes with the camouflage properties of the shelter. For these reasons, shelters are generally designed with multiple layers of fabric with air gaps in between. Next generation shelters take advantage of new coatings available to enhance the fabric material's reflective properties at selected wavelengths, allowing for a reflective insulation with the standard desert tan color. The reflective and emissive properties of the materials can be measured, but may not directly capture the resulting performance of the shelter, especially when using multiple layers.

Multiple layers create insulating air gaps between layers and reduce the solar radiation penetrating into the conditioned space, as illustrated in Fig. 1. The building envelope of the shelters contains up to three different layers: the inner liner, the skin, and the outer fly. Each layer may be a different material with different thermal properties. Analyzing the shelter as a complete system required the consideration of all three methods of heat transfer (radiation, convection, and conduction).

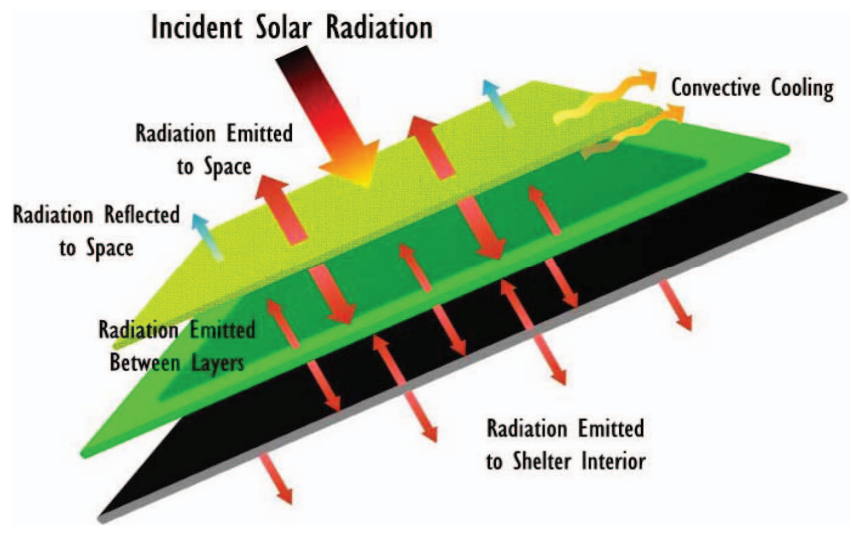

Fig. 1. Illustration of solar radiation passing through a multiple layer fabric shelter system with convective cooling occurring in outermost fly layer [3]. 


\section{TEST PROGRAM DEVELOPMENT}

There is no test standard specific to measuring the thermal performance of radiant barrier systems in temporary fabric structures for military use. In the absence of testing standards, the DoD provides guidance for the development of test programs. Fig. 2 outlines the steps required to identify the requirements and tailor existing test procedures for new systems, which include characterizing the natural and operational environment in which the system will perform.

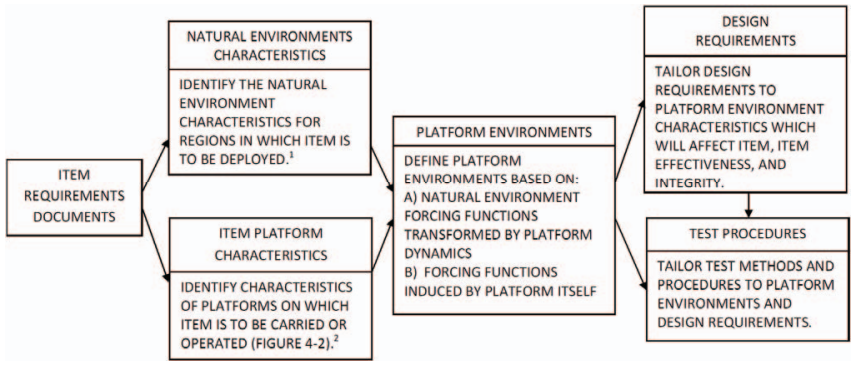

Fig. 2. Schematic showing the test program tailoring process [4].

\section{A. Environmental Conditions}

Environmental conditions vary throughout the Middle East, but overall the region is classified as hot and dry [5]. The DoD chose Kuwait as a field test location representing the extreme conditions of the Middle East to characterize the expected thermal load on the shelter, as shown in Fig. 3 and 4. For laboratory tests, the standard of $1120 \mathrm{~W} / \mathrm{m}^{2}$ and $120^{\circ} \mathrm{F}$ is used to represent "the hottest conditions exceeded not more than one percent of the hours in the most extreme month at the most severe locations" [4].

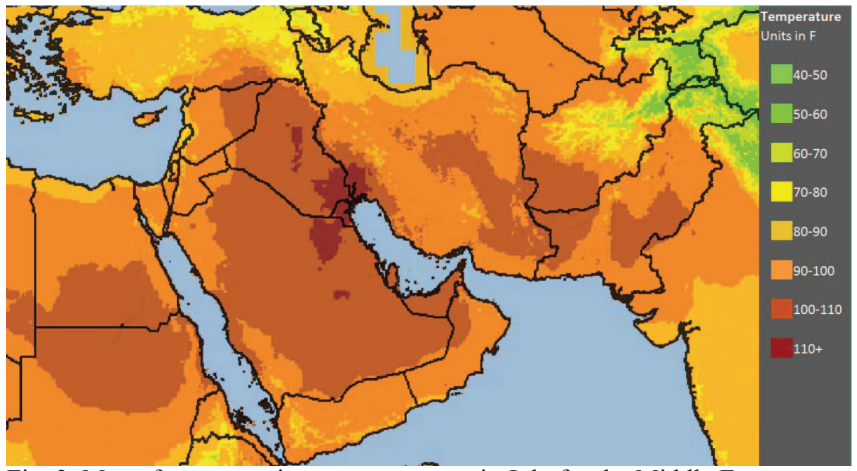

Fig. 3. Map of mean maximum temperature in July for the Middle East.

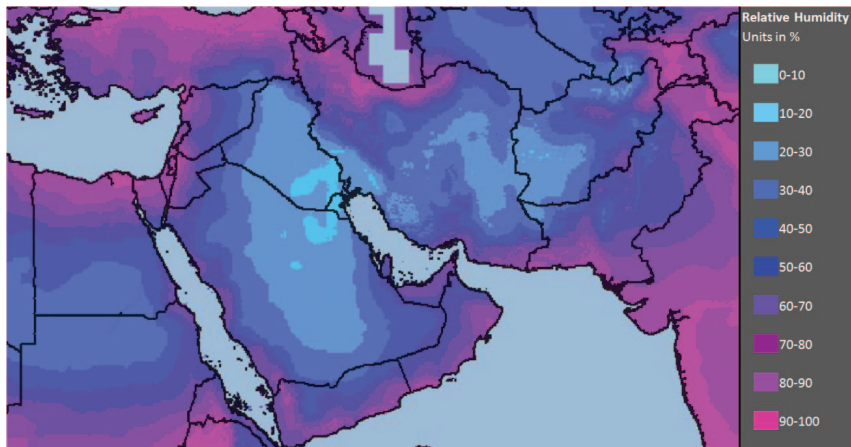

Fig. 4. Map of mean maximum relative humidity. Kuwait experiences the most extreme conditions for high temperature and low relative humidity.
The interior load is determined by each individual structure's use and the requirements of personnel and equipment inside. The standard set by Air Force operations requirements state the shelter and ECU system must provide a minimum of $30^{\circ} \mathrm{F}$ cooling with an ambient temperature of $110-125^{\circ} \mathrm{F}$. These specifications are vague with no mention of other climatic conditions such as humidity, solar radiation, or wind speed. The American Society of Heating, Refrigerating and Air-Conditioning Engineers (ASHRAE) consider an interior space comfortable with the operative temperature as high as $81^{\circ} \mathrm{F}$ during the summer if accompanied with low relative humidity [6]. The AF standard of $30^{\circ} \mathrm{F}$ cooling with an ambient temperature of $110^{\circ} \mathrm{F}$ is at the threshold of comfortable and will become uncomfortable as exterior temperatures approach $125^{\circ} \mathrm{F}$. Furthermore, the heat produced by the equipment and personnel inside must be specified as they can significantly affect the heat load.

\section{B. Operational Conditions}

In addition to the environmental conditions, the operational conditions were considered. The materials used in military structures must meet specifications other than thermal performance including hydrostatic resistance, flame resistance, light weight, high strength, and a host of others. Established testing methods are used to evaluate these other requirements and are beyond the scope of this paper, but must be considered when evaluating new materials. Furthermore, the material must withstand conditions encountered in transportation, storage, erection, use, and reconstitution.

\section{Efficiency of the Environmental Control Unit}

The ECU is an air conditioning and heating unit specifically designed for use in deployed locations. The approximately 750 pound unit produces up to 67,000 BTUH for cooling and 84,000 BTUH for heating with an air flow of 2200 cubic feet per minute. A small shelter will have one ECU while larger shelters may have multiple ECUs [7].

The efficiencies of current and future ECUs are beyond the scope of this research; however, these factors play an important role in the overall performance of the system as they are the point-of-use for energy consumption. The thermal performance of the materials and configurations of the shelter fabrics can be optimized without the use of the exact ECU.

\section{Testing Methods}

\section{A. In-situ Tests}

Three different testing methods were utilized to measure thermal performance of the shelters. The first and most accurate test was a full-scale test performed in Kuwait on shelters with different fly, skin, and liner configurations. Each shelter was outfitted with interior temperature and humidity sensors along with temperature sensors located on the surface of each layer and the air gaps between the layers. The power draw required for the ECU to maintain a set interior temperature was monitored and recorded. Additionally, a weather station was located directly outside the shelter to collect climatic data including temperature, humidity, solar 
irradiance, and wind speed and direction. While this field data is preferred, it requires extensive resources and is not practical to test every new configuration or material developed.

The second test method utilized smaller test jigs as pictured in Fig. 5 instead of full size shelters. This was a more economical field test that required much less resources. A four foot by twelve foot sample of each layer was secured over an insulated triangular jig, simulating a small shelter. A weather station collected climatic data and sensors measured the temperature of the surface of each layer and the interior of the jig. This did not require the use of air conditioning and thermal performance was judged by the interior temperature in comparison to the exterior temperature and solar irradiance. Similar to the full scale test, the constantly changing exterior temperature and varying irradiance level made it difficult to compare tests conducted at different times.

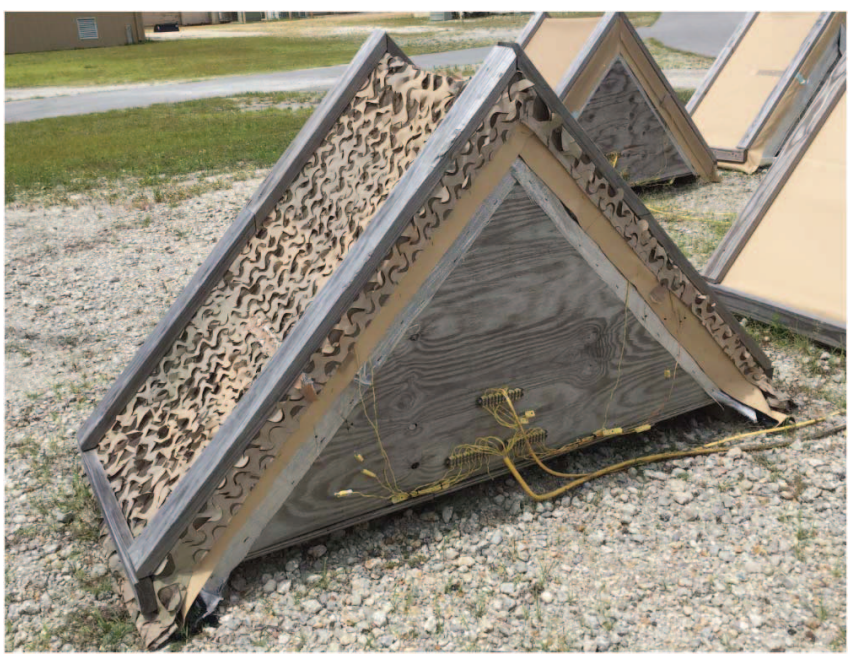

Fig. 5. Test jig configured with all three layers spaced 1.5 inches apart.

\section{B. Laboratory Tests}

Shelter manufactures utilize in-house tests to evaluate different materials and configurations, resulting in a wide range of performance measurements. The most promising setup utilized a modified hot box method to evaluate the thermal performance of the fabric materials individually and as systems of liner, skin, and fly.

The standard hot box method is a controlled laboratory experiment commonly used to measure the insulation value of construction materials either independently or as a system. This method is valid for evaluating the performance of radiant barriers in traditional construction [8]. American Society for Testing and Materials (ASTM) C1363-11 "Standard Test Method for Thermal Performance of Building Materials and Envelope Assemblies by Means of a Hot Box Apparatus" provides standards regarding hot box construction and the measurement and calculation procedures for heat transfer through the test materials [9].

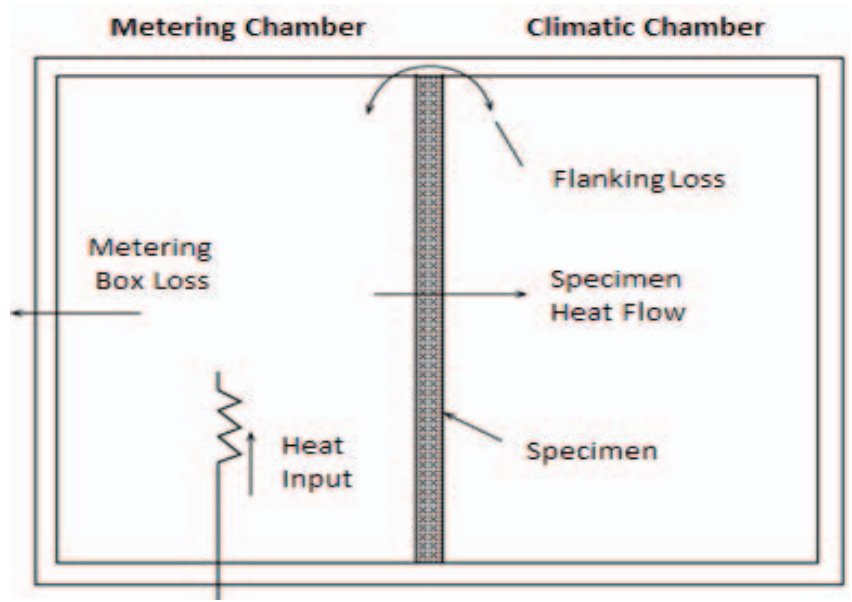

Fig. 6. Illustration of heat flow through a hot box adapted from ASTM C1363-11[9]. The heat input must be a full spectrum lamp in order to accurately evaluate the performance of radiant barriers.

Modification to the hot box's heat input was required to accurately evaluate the heat transfer through radiant barriers. The purpose of radiant barriers in the shelter systems was to reflect radiation from the sun. Therefore, a specialized heat source was required to mimic the sun. Full-spectrum lamps were available that output the spectrum of wavelengths emitted by the sun that reach the Earth's surface. The specifications for the lamp are beyond the scope of ASTM C1363-11. Therefore, it was necessary to add additional guidance.

The DoD published Military Standard 810G, Environmental Engineering Considerations and Laboratory Tests, which addressed the simulation of solar radiation. The scope included specific types of radiation sources along with parameters for total irradiance provided in Table 1, which included spectral energy distribution, irradiance uniformity, and sensor requirements. Testing procedures were also provided.

\begin{tabular}{|c|c|c|c|c|c|c|}
\hline \multirow{2}{*}{$\begin{array}{l}\text { Spectral } \\
\text { Region }\end{array}$} & \multirow{2}{*}{$\begin{array}{c}\text { Bandwidth } \\
(\mathrm{nm})\end{array}$} & \multirow{2}{*}{\begin{tabular}{|c|} 
Natural \\
Radiation
\end{tabular}} & \multicolumn{2}{|c|}{ Tolerance (\% of total) } & \multirow{2}{*}{\begin{tabular}{|c|} 
Irradiance \\
(W/m2)
\end{tabular}} & \multirow{2}{*}{\begin{tabular}{|c|} 
Spectral \\
Region
\end{tabular}} \\
\hline & & & Min & Max & & \\
\hline Ultraviolet - B & $280-320$ & 0.5 & 0.3 & 0.7 & 5.6 & 5.6 \\
\hline \multirow{2}{*}{ Ultraviolet - A } & $320-360$ & 2.4 & 1.8 & 3 & 26.9 & \multirow{2}{*}{62.7} \\
\hline & $360-400$ & 3.2 & 2.4 & 4.4 & 35.8 & \\
\hline \multirow{3}{*}{ Visible } & $400-520$ & 17.9 & 16.1 & 19.7 & 200.5 & \multirow{3}{*}{580.2} \\
\hline & $520-640$ & 16.6 & 14.9 & 18.3 & 185.9 & \\
\hline & $640-800$ & 17.3 & 12.8 & 19 & 193.8 & \\
\hline Infrared & $800-3000$ & 42.1 & 33.7 & 50.5 & 471.5 & 471.5 \\
\hline & & & & Totals & 1120 & 1120 \\
\hline
\end{tabular}

\section{DATA AND ANALYSIS}

Currently, data has been collected which used all three test methods. Each method collected data at ten second intervals and stored the data in a data logger. This allowed temperature comparisons on the interior and exterior of the shelter along with the skin temperatures of each layer and the air gap in-between. These systems of multiples layers were then compared to optimize the material and configuration of the systems. 
The full-scale tests in Kuwait are preferred as they provided real-world data. The power draw and run time of the ECU allowed direct comparison of energy usage between different configurations. They also accounted for issues such as thermal bridging of the structural members, infiltration through seams and fenestrations, and other thermal losses due to the construction of the shelter.

The test jigs provided an economical alternative to the full-scale test. They allowed for multiple different configurations to be tested simultaneously in a smaller footprint and erected in less time. The performance of the fabric system was measured by the internal temperature compared to the climatic data.

Finally the modified hot box provided the most controlled environment. This allowed for tests conducted at different times to be easily compared. However, like the test jigs, this test ignored thermal bridging and other thermal losses due to the construction of the shelter.

\section{CONCLUSION}

Geographical Information System (GIS) weather data from the Air Force $14^{\text {th }}$ Weather Squadron indicated that the Middle East is primarily a hot, dry region, and Kuwait exhibited the most extreme tendencies. This data aligned with the DoD's decision to use Kuwait as a physical test location and the specification for the shelters to perform in conditions reaching irradiance levels of $1120 \mathrm{~W} / \mathrm{m}^{2}$ and temperatures of $120^{\circ} \mathrm{F}$. The interior climate requirements were determined to be specific to the use of the shelter.

The addition of full-spectrum lamps to the hot box apparatus combined with test procedures from Military Standard $810 \mathrm{G}$ allowed for small scale simulation of solar radiation on shelter fabrics without the need for costly, fullscale tests. This standardized method allowed for repeatable results and simplified comparisons of different shelter configurations. The use of full-spectrum lamps eliminated the day-to-day variation in solar radiation and temperature at a specific location and allowed freedom to conduct tests anywhere. This method eliminated the risks associated with testing in the Middle East.

Initial tests indicated that fabric structures with radiant barriers must be tested as a system; simply summing the thermal resistance, R-values, of the individual materials and air gaps did not adequately represent the thermal performance of the system. Furthermore, the most influential variables affecting the thermal performance of a radiant barrier in traditional attic construction was shown to be local ambient temperature and humidity [10]. These variables also appeared to be key climatic factors affecting shelter thermal performance.

The continuation of this research will focus on validating the test jigs and modified hot box tests. Once validated, these tests will allow for more rapid prototyping of shelter systems at much lower costs.

\section{ACKNOWLEDGEMENTS}

The authors would like to thank Rod Fisher, Dr. Moheisen and the rest of the team at the Air Force Civil Engineer Center (AFCEC) for the wealth of information on temporary fabric structures. Also, thanks to Gabe Lehman and Celina Tent for involving the authors in the fabrication of the next generation shelters.

\section{REFERENCES}

[1] D. J. Murley, A. E. Thal Jr., L. J. Wyatt, T. W. Johannes, and A. B. Badiru, "Development of a cooling load model for geospatial analysis of energy efficient technology in austere environments," IIE Annu. Conf. Expo 2013, May 18, 2013 - May 22, pp. 1167-1176, 2013.

[2] Office of the Under Secretary of Defense for Acquisition Technology and Logistics. "Fiscal Year 2014 Operational Energy Annual Report," Rep.1-FA2A3F6, 2015.

[3] N. M. Riemer, D. Johnson, B. Kohn, S. Matheson, C. Williams, and B. Gillespie, "Designing Transportable Collectively Protective Shelters for Thermal Efficiency," 2006.

[4] Environmental Engineering Considerations and Laboratory Tests, Military Standard 810G, 2008.

[5] Global Climatic Data for Developing Military Products, Military Standard 310, 1997.

[6] ASHRAE handbook, 2009 ed., American Society of Heating, Refrigerating and Air Conditioning Engineers, Atlanta, GA, 2009, pp. 9.12 .

[7] Guide to Bare Base Mechanical Systems, Air Force Handbook 10-222 $12^{\text {th }}$ ed., 2009, pp. 61-63.

[8] C. Escudero, K. Martin, A. Erkoreka, I. Flores, and J. Sala, "Experimental thermal characterization of radiant barriers for building insulation," Energy Build., 2013.

[9] A. International, "ASTM C1363 - 11 Standard Test Method for Thermal Performance of Building Materials and Envelope Assemblies by Means of a Hot Box Apparatus 1," Am. Soc. Test. Mater., vol. 90, no. Reapproved, pp. 1-44, 2014.

[10] M. A. Medina and C. B. Young, "Evaluating the Sensitivity of Attic Radiant Barrier Performance to Climate Parameters," J. Energy Eng., vol. 134, no. 1, pp. 2-5, Mar. 2008. 